\title{
Surface analytical approaches contributing to quality assurance during manufacture of functional interfaces
}

\author{
Kai Brune ${ }^{1 *}$, Christian Tornow ${ }^{1}$, Michael Noeske ${ }^{1}$, Thorben Wiesner ${ }^{1}$, André Felipe Queiroz Barbosa ${ }^{1,2}$, \\ Stephani Stamboroski ${ }^{1,3}$, Stefan Dieckhoff ${ }^{1}$ and Bernd Mayer ${ }^{1}$
}

\author{
* Correspondence: \\ kai.brune@ifam.fraunhofer.de \\ ${ }^{1}$ Adhesive Bonding Technology and \\ Surfaces, Fraunhofer Institute for \\ Manufacturing Technology and \\ Advanced Materials IFAM, Wiener \\ Straße 12, D-28359 Bremen, \\ Germany \\ Full list of author information is \\ available at the end of the article
}

\begin{abstract}
Assessing adhesion or strength of composites or adhesive joints in a non-destructive way is highly challenging. Therefore, instead of performing retrospective quality assurance, i.e. investigating manufactured joints, it is advantageous to safeguard performance and quality of each layer and each interface already during manufacture. This approach still is challenging, as it requires a systematic quantitative evaluation of threshold criteria, but appreciably it gets more and more feasible. We present approaches for an inline-capable and non-destructive quality assurance of steps in manufacturing processes used for tailoring the state of substrate surfaces. Benefits from applying techniques for inline surface analysis like Optically Stimulated Electron Emission (OSEE) and Aerosol Wetting Test (AWT) will be detailed. The performed procedures contribute to a novel class of non-destructive testing (NDT) techniques, classified as Extended NDT (ENDT). The principle of ENDT methods is based on the detection of selected physico-chemical properties which are important for the anticipated performance of the functional interfaces in the products to be manufactured.

A prerequisite for obtaining reliable composite materials is to reproducibly prepare a suitable surface state of the substrates before the first step of a coating or bonding process. As demonstrative application scenarios, we highlight first an exemplary surface pretreatment process for steel substrates, and second the identification of a surface state for carbon fiber reinforced polymer (CFRP) adherents suitable for joining. Concerning steel substrates we investigated two types of steel both in the as-received state and a state after grinding. We demonstrate that the removal of the topmost material layer comprising the reaction layer and mechanically deformed metal grains strongly affects the properties of the resulting adherent surface. As a consequence, a material-specific time slot for a steel substrate exposure in air after grinding is suggested in which the surface properties probed by OSEE remain unchanged. Moreover, we work out that the sensitivity and accuracy of inline-capable NDT techniques allow distinguishing surface states suitable for bonding of CFRP adherents from surface states unfavourable for adhesive bonding, and we exemplarily verify this statement for bonding processes applying freshly ground CFRP or, respectively, CFRP covered with thin layers of release agents.
\end{abstract}

Keywords: Online surface monitoring; Extended non-destructive testing; Carbon fibre reinforced plastics; Detection of release agent; Pretreatment of steel; Ageing of steel surfaces; Quality assurance in bonding processes

\section{Springer}

(c) 2015 Brune et al.; licensee Springer. This is an Open Access article distributed under the terms of the Creative Commons Attribution License (http://creativecommons.org/licenses/by/4.0), which permits unrestricted use, distribution, and reproduction in any medium, provided the original work is properly credited. 


\section{Background}

Implementing reliable process steps like application, modification or removal of thin layers on substrates or adherents is crucial in a wide field of technological manufacture. Exemplarily, coating or adhesive bonding processes rely on a sequence of layeroriented procedures comprising substrate cleaning, pre-treatment and, finally, the application of a fluid system which during the manufacture wets the substrate surface, hardens and forms a coating or an adhesive layer [1-4]. A huge variety of possible substrate materials is technologically used for distinct applications, ranging from steel for off-shore construction [5], bridge [6], pipeline [7] or ship building [8] to Carbon Fiber Reinforced Polymers (CFRP) for the manufacture of structural light-weight components in the aeronautics industry. The surface state of steel or CFRP substrates during coating or adhesive bonding governs the performance and quality of the manufactured products. Reliably coating steel substrates or joining modern polymer-based lightweight materials like CFRP using adhesive bonding technology will significantly profit from up-to-date quality assurance not only of the produced joints but also of the adherent surfaces entering the bonding process.

In the case of steel, the corrosion-protective effect of coatings on steel substrates strongly depends on the metal pre-treatment [9]. Concerning CFRP, in principle adhesive bonding is an optimum technique for joining light-weight structures based on heat-sensitive plastics, but difficulties in assessing the bond quality by non-destructive testing (NDT) limit the use for aircraft structural assembly. In consequence, certification by the regulation authorities is restrictive. For both steel and CFRP structures the coating or bonding process may be envisioned to take place starting from recently manufactured and thoroughly cleaned adherents in a well-climatised manufacturing site, or it may deal with already utilised devices when a repair is performed in a workshop environment.

Concerning steel, the surface state is checked for safeguarding the quality when manufacturing coated steel substrates or adhesive joints comprising steel adherents [13]. Investigations of steel surfaces using Optically Stimulated Electron Emission (OSEE) were reported during plastic deformation of steel samples in vacuum at low temperatures [10], and a modified Geiger counter was used to measure the exoelectron emission from iron or nickel subjected to friction and wear or after exposure to gaseous environments like water vapor or oxygen at various pressures [11]. The OSEE signal was indicated to be sensitive not only to the state and thickness of the reaction layers on the metal surface [11] but also to contaminations, e.g. grease layers, on steel surfaces - in concentrations which result in effects on adhesion properties [12,13]. Referring to parameters affecting the strength of metal/polymer interphases, for aluminum and titanium the initial bond strength of metal/polymer bonds and their long-term performance were reported to depend on the oxide layer formed on metal surfaces and its environmental stability, respectively [14], and for adhesive bonding with mild steel adherents it was shown that joints prepared under $7 \%$ r.h. result significantly stronger than joints prepared under $56 \%$ r.h. [15]. Especially when aiming at a pretreatment for bonding processes an increase of the surface roughness may be recommendable for improving the bond strength [16]. Thus, the surface preparation of steel substrates and their exposure before and during manufacture or repair will strongly influence the strength and durability of the resulting coated steel substrates or adhesive joints comprising steel adherents. Among mechanical 
surface preparation grit blasting, e.g. using abrasive impact of sand or corundum particles, or grinding are commonly used as pretreatment processes for steel adherent surfaces [17-20] or steel surfaces before painting [21]. In the present contribution, we apply a manual dry grinding process of cleaned specimens for the mechanically abrasive pretreatment of steel surfaces. We present the results of OSEE investigations of two distinct types of steel, and the as-received and a freshly ground surface state are characterized. Moreover, we line out the surface properties after distinct exposures to air and immersion in water, profiting from the advantage of the online technique that superficial changes can be detected very quickly. Related to the significance of reproducibly equal conditions to ensure the quality of bonding systems, we suggest a span for the open time before applying a coating or an adhesive system.

Concerning CFRP, manufacturing and in-service effects were shown to influence the mechanical performance of joints prepared from such polymer adherents [22,23]. Exemplarily, within the ENCOMB project Markatos et al. demonstrated that the mode 1 $\left(G_{1 c}\right)$ interlaminar fracture toughness of adhesively bonded joints strongly depends on the surface state of the CFRP panels introduced into the bonding process. Exemplarily, when silicone-based release agents are used in a molding process during the manufacture of CFRP, silicone concentrations in the range of 5 to 20 atom \% (according to XPS investigations) can typically be obtained [23]. Different further factors were shown to result in a decrease of the pristine $G_{1 c, p}$ value. As compared to pristine dry and clean reference adherents, very pronounced effects were obtained when applying approximately $1 \mathrm{~nm}$ of a release agent, resulting in $\mathrm{G}_{1 \mathrm{c}, \mathrm{p}}$ being lowered by nearly $70 \%$. These results are at the basis of the investigations detailed in this work, because before the adhesive bonding process the surface state of the adherents had been investigated applying NDT within an extended NDT approach. Therefore, the mode $1\left(\mathrm{G}_{1 \mathrm{c}}\right)$ interlaminar fracture toughness values reported by Markatos et al. are detailed in Figure 1.

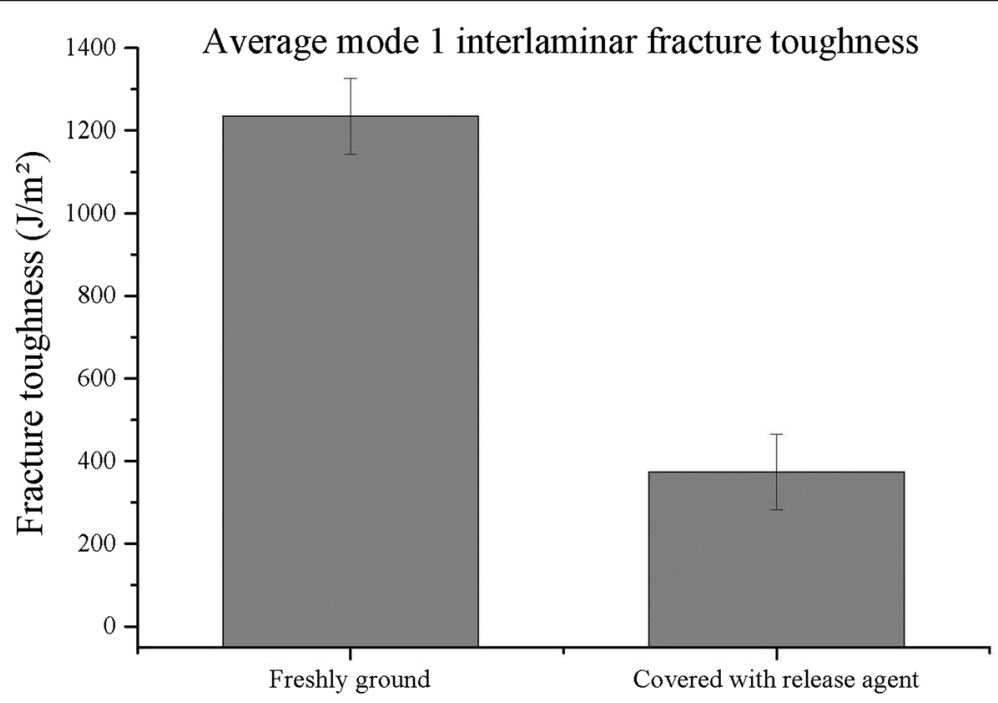

Figure 1 Mode $1\left(G_{1 c}\right)$ interlaminar fracture toughness values reported by Markatos et al. [23] for freshly ground CFRP adherents and CFRP adherents covered with release agent, respectively. Before the bonding was performed by these authors quality assurance measures reported in the present contribution had been performed. 
Basically, such huge influence of contaminants on bond strength as demonstrated within the ENCOMB project clearly emphasizes the need to monitor the state of adherent surfaces before introducing them into a bonding process. A non-destructive approach may be offered by performing a water break test. However, the wetting behavior of the CFRP panels will be affected in a complex way by the roughness of ready-to-bond CFRP surfaces. Alternatively, Optically Stimulated Electron Emission (OSEE) permits a considerable performance for surface investigations of CFRP under ambient conditions, as detailed particularly by Parker and Waghorne [22]. However, OSEE has not yet achieved a widespread use for investigating the surface state of CFRP substrates exhibiting contaminations considered relevant, e.g., in aeronautical use. As a forward-looking contribution, the results presented here were obtained in the frame of the ENCOMB project and with CFRP panels prepared correspondingly and in parallel to the adherents used by Markatos et al. [23]. OSEE [24] and Aerosol-Wetting-Test (AWT) [25,26] were assessed and advanced with respect to their applicability as ENDT techniques for sensitively indicating the presence of intentionally deposited and around $1 \mathrm{~nm}$ thin layers of a release agent on CFRP sample surfaces.

\section{Methods}

In this chapter, experimental details are presented. The surface analytical tools are described, and the implementation of the scenarios for steel and CFRP applications is depicted.

\section{Analytical tools for extended NDT of surfaces}

Optically Stimulated Electron Emission (OSEE) experiments were performed under ambient conditions with a Surface Quality Monitor SQM200 (purchased from Photo Emission Tech., Inc. (PET), USA). Concerning the principle of an OSEE measurement, the sample surface is exposed to ultra-violet light of a mercury vapour lamp with prominent emission maxima at 4.9 and $6.7 \mathrm{eV}$. Due to the work function of the respective substrate surface amounting to approximately $5 \mathrm{eV}$, the latter emission maximum essentially contributes to the photoelectrons emitted by the sample surface, and emitted electrons will exhibit kinetic energies of less than approximately $2 \mathrm{eV}$. Such photoelectron energy results in a clearly sub-micrometer information depth of this method when investigating the surface of a solid sample. The interaction of the emitted photoelectrons with the ambient atmosphere is predominated by an electric field effective at the sensor to an extent which permits sensor surface distances in the millimeter range during OSEE measurements. Carefully controlling the distance between the sensor and the surface is a prerequisite for effectively applying the set-up sketched in Figure 2.

For mounting the substrates to be analysed, the OSEE device is provided with an electrically conductive and earthed moving table, on which the analyte sample is positioned by movements in two perpendicular horizontal directions under the sensor. The vertical distance between the sample surface and the sensor is set using a micrometer screw attached to the holder of the sensor. Controlling the sample-to-sensor distance is essential during the OSEE measurements, and during the reported surface analytical investigations of the flat steel sheets the sample-to-sensor distance is maintained constant. A surface scan is then performed, with the table being programmed to move 


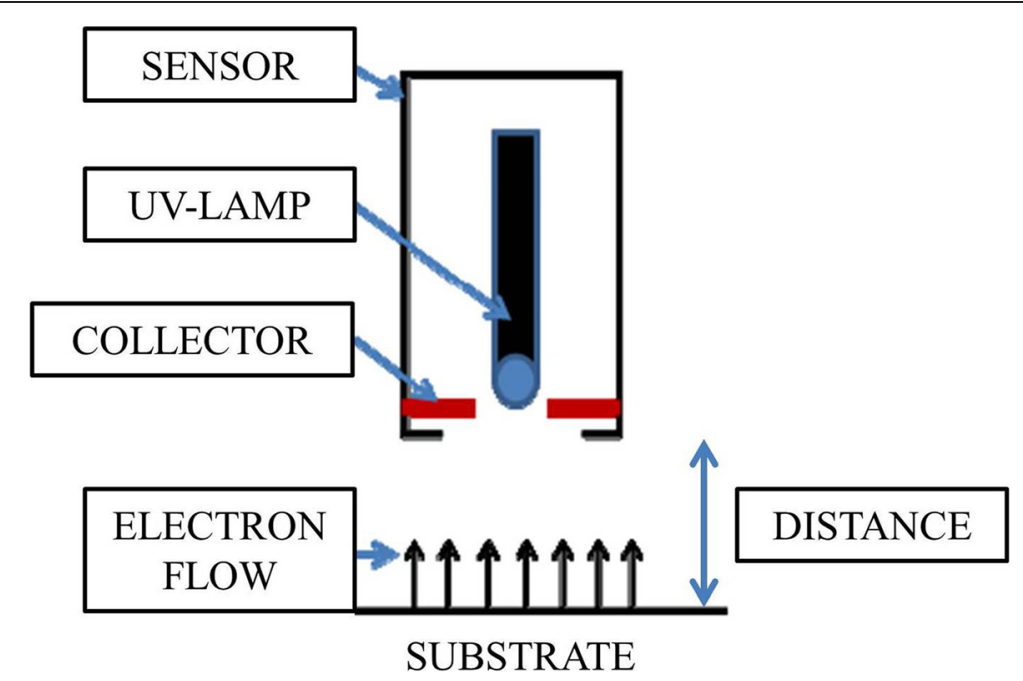

Figure 2 Sketch showing basics of a set-up relevant for performing non-destructive surface analysis using Optically Stimulated Electron Emission (OSEE).

according to a step size and a number of steps (in both horizontal directions) defined by the user applying a software associated to the machine. As the scan advances, a photocurrent is obtained for each part of the scanned surface, and a dimensionless value further on denoted as the OSEE signal is indicated on a monitor. At the end, a digital worksheet with the emission values for the entire analyzed sample, i.e. an OSEE map, is presented as a result of the test performed. In detail, during the scanning of the steel samples the panels were positioned at a distance of $3.19 \mathrm{~mm}$ below the OSEE sensor, and when acquiring averaged OSEE intensities the parameters of the horizontal moving of the table were set as $1 \mathrm{~mm}$ step size and 25 steps in both directions.

The Aerosol Wetting Test (AWT) is a method to characterise the wetting properties of extended surfaces. The Aerosol Wetting Test was developed [25] to overcome drawbacks of contact angle measurements and the water break test. Depending on the surface state and surface energy, droplets of an aerosol form wide or narrow drops when applied to surfaces. For a defined liquid volume, the size of a single droplet depends directly on the contact angle. When several droplets are deposited, the property of a surface to be wetted can be characterised by the droplet size distribution. If the surface energy of a sample is low, e.g. due to contaminations like release agents, narrow drops will be formed on the surface. If the surface energy of a sample is high, wide drops will form. In the experiments, an ultrasonic atomiser nozzle was used to create an aerosol of small water drops with a narrow drop size distribution. This nozzle was fed by a syringe pump ensuring a constant water flow. By a constant airflow these drops are sprayed onto the surface of the sample. Depending on the surface energy of the sample, the area density of wide droplets increases with increasing the amount of water deposited. The resulting drops are imaged by a camera (Olympus, ColorView III) positioned perpendicular to the surface. Using an analysis software, the images are processed. The processing comprises background subtraction and quality refining; in this way structures or scratches on the sample are considered. Afterwards the diameters of the drop sizes are measured and classified. Using a twoparameter fit, the results are fitted to match a Rosin-Rammler drop-size distribution. The mean distribution width is used to rate the fitting results. 
Additionally, steel surfaces and surfaces of CFRP panels were characterised using vacuum-bound instrumental analysis. Investigations of the surface composition were performed with X-ray Photoelectron Spectroscopy (XPS), and for XPS investigations pieces were cut out of the several centimetres wide original CFRP samples. XPS spectra with an information depth of around $10 \mathrm{~nm}$ were taken using a Kratos Ultra system applying excitation of photoelectrons by monochromatic $\mathrm{Al}_{\mathrm{K} \alpha}$ radiation within an area of approximately $0.2 \mathrm{~mm}^{2}$. The system was operated at a base pressure $4 \times 10^{-8} \mathrm{~Pa}$, the sample neutralization was performed with low energy electrons $(<5 \mathrm{eV})$. An electrostatic lens was used, the take-off angle of electrons was $0^{\circ}$ with respect to the surface normal, and the pass energy was fixed to $20 \mathrm{eV}$ (or, respectively, $40 \mathrm{eV}$ in case of some less concentrated constituents) in high resolution spectra and $160 \mathrm{eV}$ in survey spectra. Elemental ratios were calculated based on the area of the peaks and considering relative sensitivity factors.

Investigations of the surface structure of small CFRP and steel pieces were performed with Scanning Electron Microscopy (SEM), applying a Field Emission Scanning Electron Microscope (FESEM) of type FEI Helios 600 (DualBeam). The specified resolution is $0.9 \mathrm{~nm}$ at $15 \mathrm{kV}$ at optimal working distance, and $1 \mathrm{~nm}$ at $15 \mathrm{kV}$ at the coincidence point. Energy Dispersive X-ray (EDX) investigations with an information depth of a few micrometers were performed in $200 \mu \mathrm{m}$ wide regions of steel samples using an acceleration voltage of $20 \mathrm{kV}$ for the incident electron beam.

\section{Implementation of scenarios relevant for steel application}

Steel sample panels of type QD (ISO 3574 type CR1, CRS SAE 1008/1010) with a thickness of $0.5 \mathrm{~mm}$ and a smooth surface were obtained from Q-Lab Deutschland GmbH. According to the material specification the chemical composition of SAE 1008/1010 steel panels is based on iron containing maximum 0.60 weight $\%$ of manganese, maximum $0.15 \%$ of carbon, maximum $0.030 \%$ of phosphorus, and maximum $0.035 \%$ of sulfur [27]. As a second steel material stainless steel 1.4301 was purchased from Rocholl GmbH (Aglasterhausen, Germany), and its chemical composition is based on iron containing maximum 0.07 weight \% of carbon, from $17.5 \%$ to $19.5 \%$ of chromium, and from $8.0 \%$ to $10.5 \%$ of nickel [28].

Cleaning of steel samples was done by wiping the surfaces with a cellulose tissue soaked with isopropanol. For the pretreatment of steel surfaces three kinds of grinding papers were used, in all cases waterproof silicon carbide papers with grit sizes of 80, 320 and 800 mesh, from Hermes Schleifmittel GmbH \& Co. KG or from Struers GmbH respectively. The manual dry grinding process was subdivided in two steps. After evaluating the effect of grinding with papers exhibiting distinct grit sizes for the final finish, a two-step grinding process was established. The first step included the removal of the topmost material layer with a thickness of 10 to $15 \mu \mathrm{m}$ - as determined gravimetrically - using the grinding paper with a grit size of 320 mesh. Subsequently, for obtaining a smooth surface finish the 800 mesh grinding paper was applied. Air exposure of ground steel surfaces was performed at room temperature at a relative humidity around $49 \%$ r.h.

\section{Implementation of scenarios relevant for CFRP application}

Two scenarios of primary importance for aircraft manufacturers applying carbon-fibre reinforced polymers (CFRP) were investigated with respect to the requirements they impose for extended NDT technologies. 
The CFRP material exhibited fibres arranged in UD layers and a thermoset matrix (T700 low density carbon fibers and HexPly ${ }^{\oplus}$ M21 matrix from Hexcel). Clean untreated reference CFRP samples were obtained by grinding until a fibre layer was reached and cleaned according to standards from aircraft manufacturers. Starting from such sample surfaces, as one of the factors effective in production layers or - after aspired cleaning - traces of silicone-based release agents were considered as a main scenario, and CFRP samples were dipped under defined conditions into a solution of Frekote $700 \mathrm{NC}$ dissolved in hexane. The samples were dried for $30 \mathrm{~min}$ at room temperature and subsequently heated for $60 \mathrm{~min}$ at $80^{\circ} \mathrm{C}$ in an air circulating oven [23]. Based on XPS investigations, the coverage of CFRP surfaces with a well-defined amount of release agent was adjusted and confirmed at several surface positions.

\section{Results and discussion}

For the investigations detailed in this chapter, first Optically Stimulated Electron Emission (OSEE) was consciously selected to be the ENDT tool for investigating the surface state of steel samples, and the results of the respective investigations are lined out. Then, the capacity of two selected Extended Non-Destructive Testing (ENDT) devices for revealing the presence and amount of silicone-based release agent on Carbon Fiber Reinforced Polymer (CFRP) sample surfaces is highlighted, with the focus being on Aerosol Wetting Test (AWT) and OSEE investigations.

\section{OSEE-based surface quality assurance for steel pre-treatment processes}

In the frame of a preliminary survey, steel surfaces with distinct roughness were investigated by OSEE after dry grinding of the SAE 1008/1010 steel substrates with distinct $\mathrm{SiC}$ grit-based grinding papers. In detail, grit sizes of 80,320 or 800 mesh, respectively, were applied in a one-step, dry grinding process which comprised both the removal of the topmost material layer and the surface finish. After the removal of approximately $20 \mu \mathrm{m}$ of material, two sets of samples were prepared, and the samples of the first set were exposed to air for 1 minute whereas the samples of the second set were stored in air for 3 minutes. At least one minute of air exposure was applied because the scanning of the steel substrates during the obtained OSEE took around one minute. The obtained OSEE intensities are shown in Figure 3.

These results indicate that for all the applied grit sizes the OSEE intensity amounts to values around 580 a.u. after 1 min of air exposure and around 520 a.u. after 3 min of air exposure, with respective standard deviations between 20 a.u. and 40 a.u. of the OSEE intensity. From these findings we infer that - in contrast to the time period of air exposure - the roughness of the ground steel surface does not significantly influence the OSEE intensity.

The surface structure of SAE 1008/1010 steel samples was characterized, and in Figure 4 scanning electron microscopic results obtained are shown. The lateral contrast in the $100 \mu \mathrm{m}$ wide SEM images is dominated by rather linear and parallel structures undulating, coarsely speaking, from the left side of the respective SEM image to the right side. These features are interpreted to result from the rolling process of the as-received steel surface and, respectively, the two-step grinding process in case of the surface finally ground with the 800 mesh $\mathrm{SiC}$ grinding paper. The rolling process 
$\mathbf{A}$

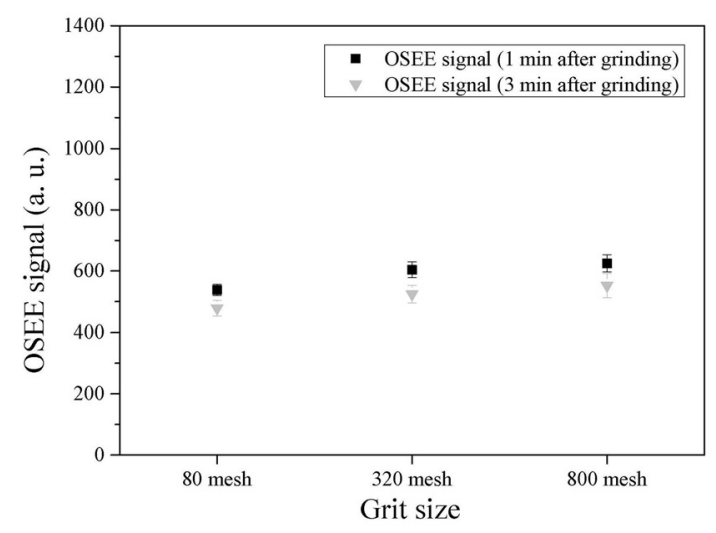

B

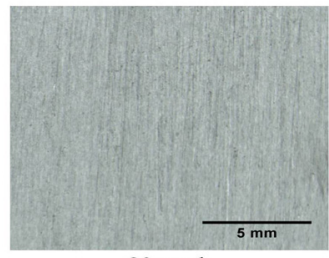

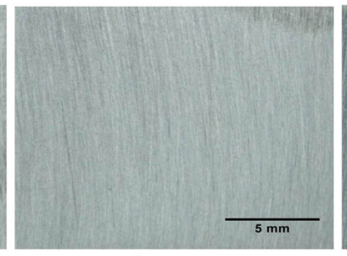

320 mesh

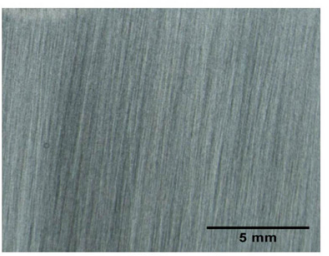

800 mesh

Figure 3 Results of non-destructive surface analysis using Optically Stimulated Electron Emission (A) and photographic documentation (B) for grinding surfaces of SAE 1008/1010 steel substrates using grinding papers with SiC grit sizes of 80,320 , and 800 mesh and then exposing them in air for $1 \mathrm{~min}$ or $3 \mathrm{~min}$.

appears to leave regions with some undercut of the mechanically flattened steel surface, and the grinding process here and there leaves blades with micrometer dimensions behind.

In addition to changing the structure of the steel surface, the composition of the SAE steel surface after grinding differs from the composition before grinding. Following Table 1 and Table 2, evidence is furnished by EDX and supplemental XPS investigations which gather surface concentrations on the topmost surface layer with a thickness of a few micrometers and around ten nanometers, respectively. Generally speaking, in the

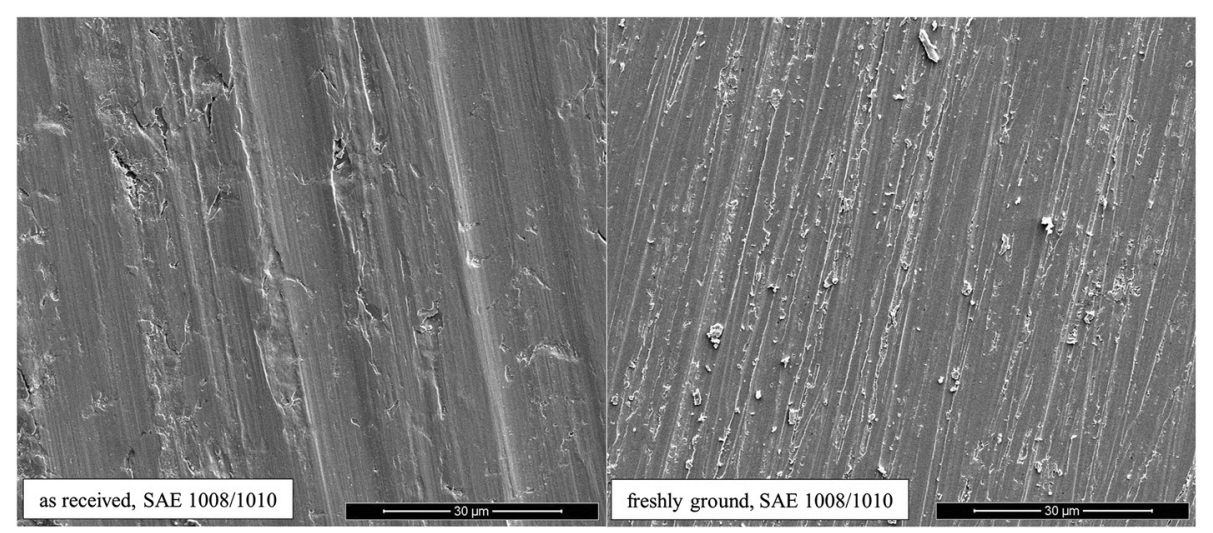

Figure 4 Scanning Electron Microscopy (SEM) based on secondary electron detection during imaging $100 \mu \mathrm{m}$ wide regions of the as-received and the ground state of surfaces of SAE 1008/1010 steel. 
Table 1 Concentrations of elements in a some micrometers thick surface region, given in atom\% disregarding measured carbon contributions, as obtained applying Energy-Dispersive X-ray Analysis (EDX) investigations of SAE steel before/after grinding

\begin{tabular}{llllllllllllllll}
\hline Sample & Zn & Fe & Mn & $\mathbf{C r}$ & $\mathbf{C a}$ & $\mathbf{S i}$ & $\mathbf{C l}$ & $\mathbf{S}$ & $\mathbf{P}$ & $\mathbf{O}$ & $\mathbf{N}$ & $\mathbf{C}$ & $\mathbf{T i}$ & $\mathbf{C u}$ \\
\hline SAE steel, as-received and cleaned & - & 95.7 & 0.7 & 0.2 & - & 0.2 & - & - & - & 3.0 & - & - & 0.1 & - \\
SAE steel, ground, $72 \mathrm{~h}$ in air & - & 96.8 & 0.4 & 0.1 & - & 0.7 & - & - & - & 1.7 & - & - & 0.1 & 0.2 \\
\hline
\end{tabular}

as-received state manganese species are enriched close to the surface as compared to iron species, and grinding removes the surface region showing this enrichment and brings about an increase of the iron concentration close to the surface. XPS investigations indicate that after grinding the concentration ratio between metallic and oxidised iron species amounts to 0.44 which is approximately 15 times higher than in the asreceived state. The surface termination of the as-received and cleaned steel panel appears to be characterised by a more than $8 \mathrm{~nm}$ thick oxide-based reaction layer.

Moreover, Table 2 lists XPS results obtained when grinding steel samples of type 1.4301 and exposing them to dry air for distinct times. In the as-received state carbon-containing species dominate the topmost surface region. Iron and chromium are detected in a concentration ratio of approximately 3:1, and these constituents are detected both in the metallic as in oxidized states which indicates an average reaction layer thickness smaller than $10 \mathrm{~nm}$ and slightly thinner than in the case of the SAE steel. Grinding removes the surface region, and after grinding the concentration ratio between metallic and oxidised iron or chromium species is approximately threefold increased as compared to the as-received state. After one minute of exposure to air, the thickness of the reaction layer is similar as in case of the SAE steel, and after four hours the thickness of this oxide-based layer is significantly increased without having yet reached the reaction layer thickness of the as-received steel.

Effects of grinding the SAE steel and the 1.4301 steel samples, respectively, were also monitored using OSEE. While the OSEE map shown in Figure 5 indicates separate OSEE signals measured at individual positions of the sample surface, the signal intensities displayed in Figures 3, 6, 7 and 8 refer to the average OSEE signal of the samples - obtained after a statistical analysis of the OSEE values measured at approximately 100 positions during scanning of the surface, and the standard deviation of this signal is displayed in the error

Table 2 Concentrations of elements in an approximately $\mathbf{0 . 0 1}$ micrometer thin surface region, given in atom \%, as obtained applying XPS

\begin{tabular}{|c|c|c|c|c|c|c|c|c|c|c|c|c|c|c|}
\hline Sample & $\mathrm{Zn}$ & $\mathrm{Fe}$ & $M n$ & $\mathrm{Cr}$ & $\mathrm{Ca}$ & $\mathrm{Si}$ & $\mathrm{Cl}$ & $S$ & $\mathbf{P}$ & 0 & $\mathbf{N}$ & C & {$\left[\mathrm{Fe}^{0}\right] /\left[\mathrm{Fe}^{\mathrm{ox}}\right]$} & {$\left[\mathrm{Cr}^{0}\right] /\left[\mathrm{Cr}^{\mathrm{ox}}\right]$} \\
\hline $\begin{array}{l}\text { SAE steel, as-received } \\
\text { and cleaned }\end{array}$ & 1.1 & 12.5 & 4.0 & - & 0.7 & 1.2 & 0.5 & 0.2 & 0.3 & 46.4 & 0.5 & 32.5 & 0.03 & - \\
\hline $\begin{array}{l}\text { SAE steel, ground, } \\
1 \text { min in air }\end{array}$ & - & 29.4 & 0.2 & - & - & - & - & - & - & 41.6 & - & 28.8 & 0.44 & - \\
\hline $\begin{array}{l}\text { Steel } 1.4301 \text {, as-received } \\
\text { and cleaned }\end{array}$ & 0.5 & 6.7 & 0.5 & 2.3 & 1.2 & - & 1.2 & 0.4 & - & 32.3 & 1.4 & 53.0 & 0.15 & 0.08 \\
\hline $\begin{array}{l}\text { Steel } 1.4301, \text { ground, } \\
1 \text { min in air }\end{array}$ & - & 20.5 & 2.2 & 7.9 & - & - & - & - & - & 37.3 & 1.2 & 30.9 & 0.41 & 0.30 \\
\hline $\begin{array}{l}\text { Steel } 1.4301 \text {, ground, } \\
30 \text { min in air }\end{array}$ & - & 22.4 & 2.5 & 7.8 & - & - & - & - & - & 38.8 & 1.1 & 27.4 & 0.37 & 0.30 \\
\hline $\begin{array}{l}\text { Steel 1.4301, ground, } \\
4 \mathrm{~h} \text { in air }\end{array}$ & - & 18.1 & 1.7 & 6.7 & - & - & - & - & - & 41.2 & 0.6 & 31.7 & 0.28 & 0.25 \\
\hline
\end{tabular}

The indicated values are due to averaging the results in two positions per sample, and signal ratios are given between metal-related and oxidized iron and chromium species. 


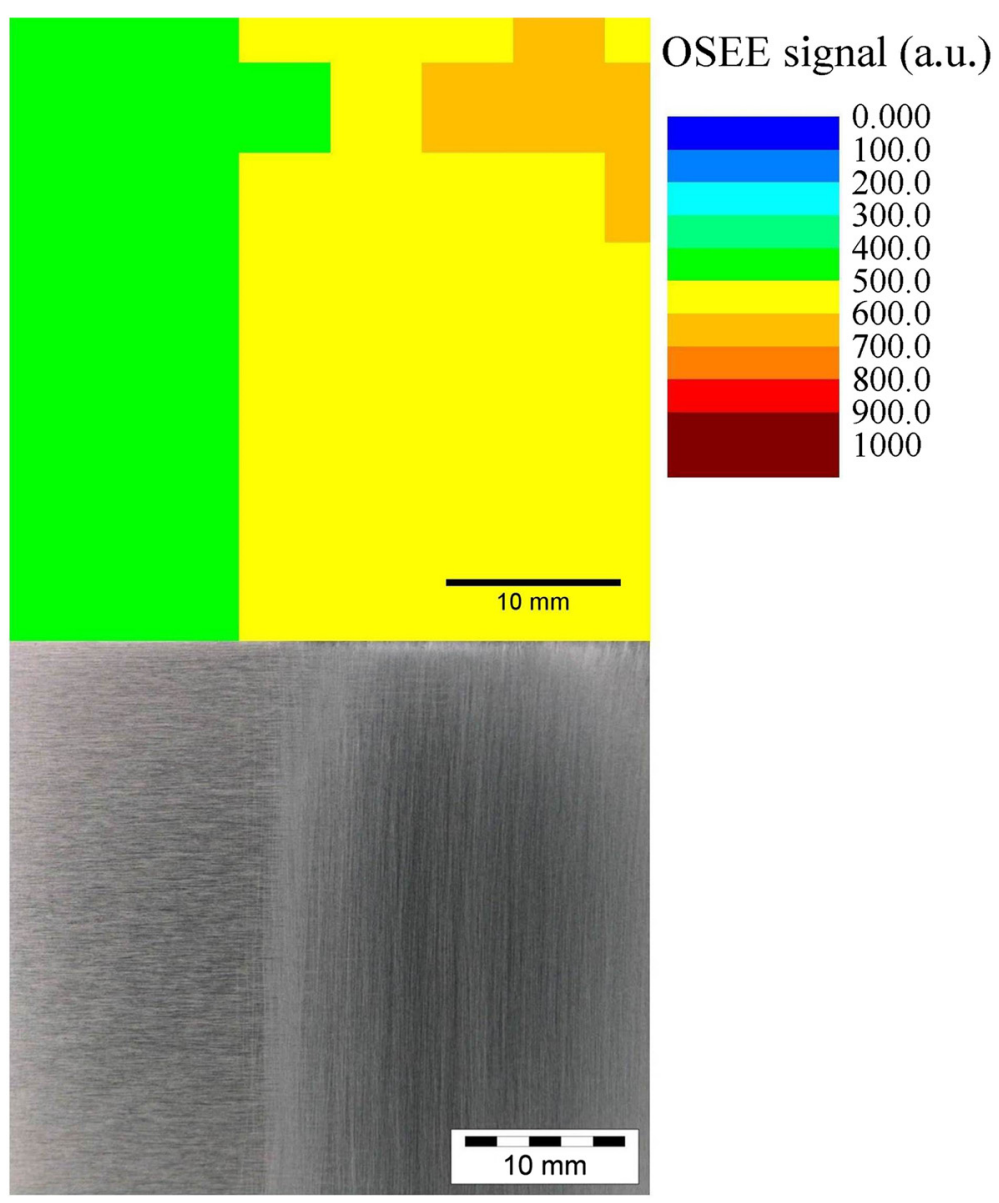

Figure 5 Results of non-destructive surface analysis using Optically Stimulated Electron Emission (OSEE) leading to an OSEE map (topmost image) displaying the local distribution of OSEE signals, and photographic image of the SAE 1008/1010 steel substrate surface. The surface states are as-received and cleaned (on the left side) and ground (on the right side).

bar. Moreover, the electron emission of the two types of steel was investigated under continued exposure in air and also in water.

In the topmost part of Figure 5 an OSEE map displaying the local distribution of OSEE signals is shown, and below a photographic image of the investigated SAE 1008/1010 steel substrate is presented. The as-received and cleaned surface can clearly be distinguished from the ground surface state on the detail of an OSEE map measured with a step size of $5 \mathrm{~mm}$ of the moving table, as well as on the photograph.

Based on Figure 6 and the OSEE results displayed, we infer that OSEE investigations allow for differentiating two types of steel and their respective surface states since asreceived or freshly ground SAE 1008/1010 steel shows different OSEE signals than asreceived or freshly ground steel 1.4301. In detail, in both of the investigated surface states the steel SAE1008/1010 shows a higher signal than the steel 1.4301. And for both types of steel we observe a clearly increased electron emission as a consequence of the grinding process. These findings may be related to the SEM, EDX and XPS results presented in Figure 4 and in Tables 1 and 2, respectively. These investigations show that the grinding process results in strong changes of the structure and the composition of the substrate surface, and the XPS investigations indicate that exposure of freshly 


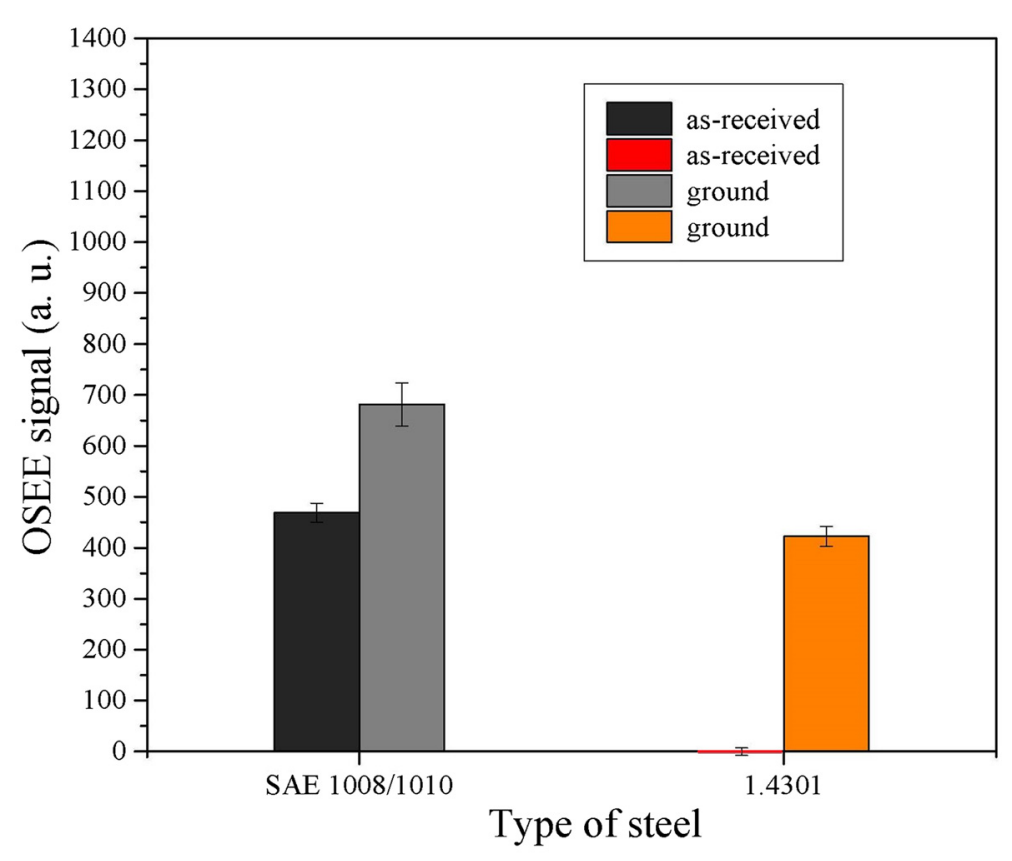

Figure 6 Results of non-destructive surface analysis using Optically Stimulated Electron Emission (OSEE) for two types of steel, namely SAE 1008/1010 steel and steel 1.4301, in two distinct surface states, namely as-received and ground.

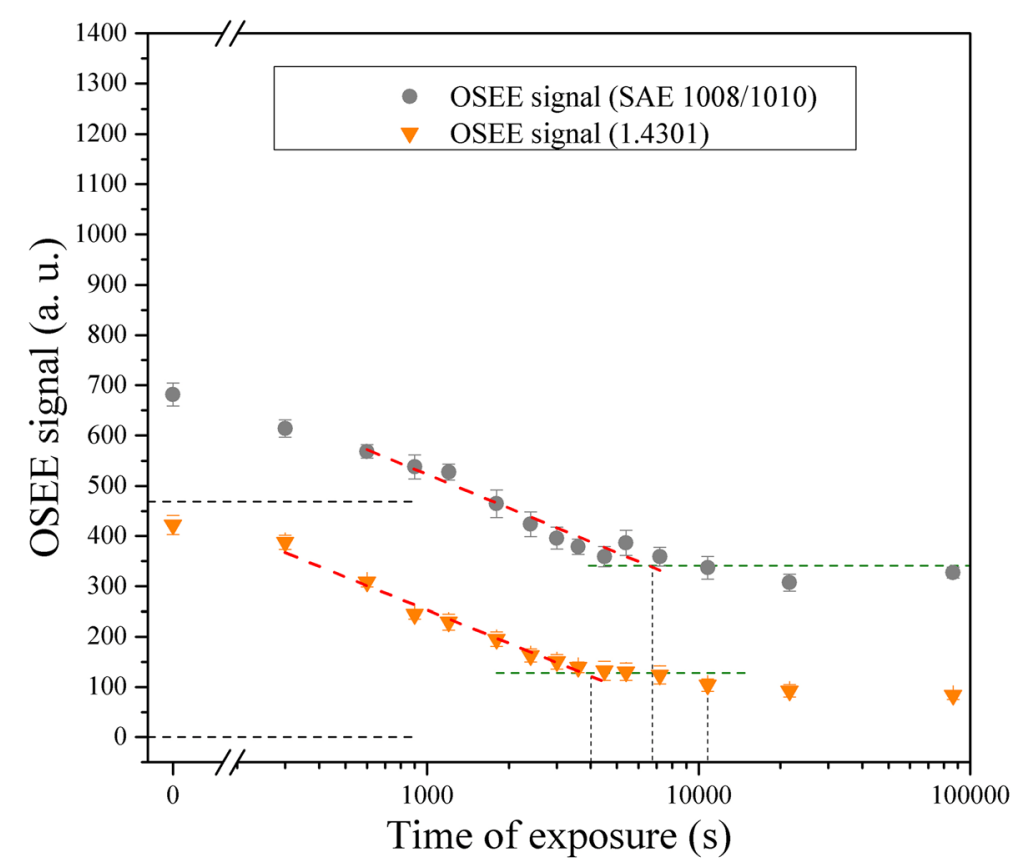

Figure 7 Results of non-destructive surface analysis using Optically Stimulated Electron Emission (OSEE) for freshly ground SAE 1008/1010 and 1.4301 steel during exposure in dry air. The horizontal dashed lines at the left side of the plot indicate the OSEE signals of as-received steel samples. Horizontal dashed lines at the right side indicate OSEE signals remaining basically unchanged after approximately two hours of exposure in air. 
ground substrates of steel 1.4301 results in changes of the surface composition and, especially, in an increased thickness of the reaction layer on top of the surface. Consequently, we applied OSEE to characterize the surface state of freshly ground steel substrates during continued exposure in dry air. The obtained results are displayed in Figure 7 for the steel samples of type SAE1008/1010 and 1.4301, respectively. Coarsely speaking, the OSEE signal significantly decreases during at least one hour for both types of steel, according to a first regime of substrate behaviour. After this phase - in a second regime of substrate behaviour - for two hours no significant change of the OSEE signals is detected. A graphical evaluation determining the intersection of both of these regimes for both types of steels reveals that the OSEE signal of steel 1.4301 reaches the second regime significantly earlier than the OSEE signal of SAE1008/1010 steel. This observation indicates that the time span for reaching the intersection is material-dependent.

Finally, Figure 8 shows effects of water immersion on the OSEE signal obtained for freshly ground SAE1008/1010 steel. We infer that an immersion of the SAE steel panels in water clearly decreases the OSEE signal. As such effect on the surface state of the steel already is observed after 90 seconds of immersion in water, we decided not to apply a water-based AWT for a non-destructive testing of the steel samples. Moreover, as the changes of the surface state are effective much faster than during exposure of ground steel sheets in air we may infer that wet grinding processes will result in distinct surface states of steel substrates as compared to dry grinding.

Subsequently, we will discuss our findings with respect to their relevance for coating or adhesive bonding processes. Generally speaking, a reproducible state of the substrate surface may be obtained using as-received panels which had been stored in air for several weeks before being cleaned or panel surfaces obtained after grinding and exposure in air. As a mechanically abrasive pretreatment will remove surface layers on the as-received samples formed in long-term contact between the panels and the surrounding air, the freshly ground steel surface may need time to kind of get equilibrated in the

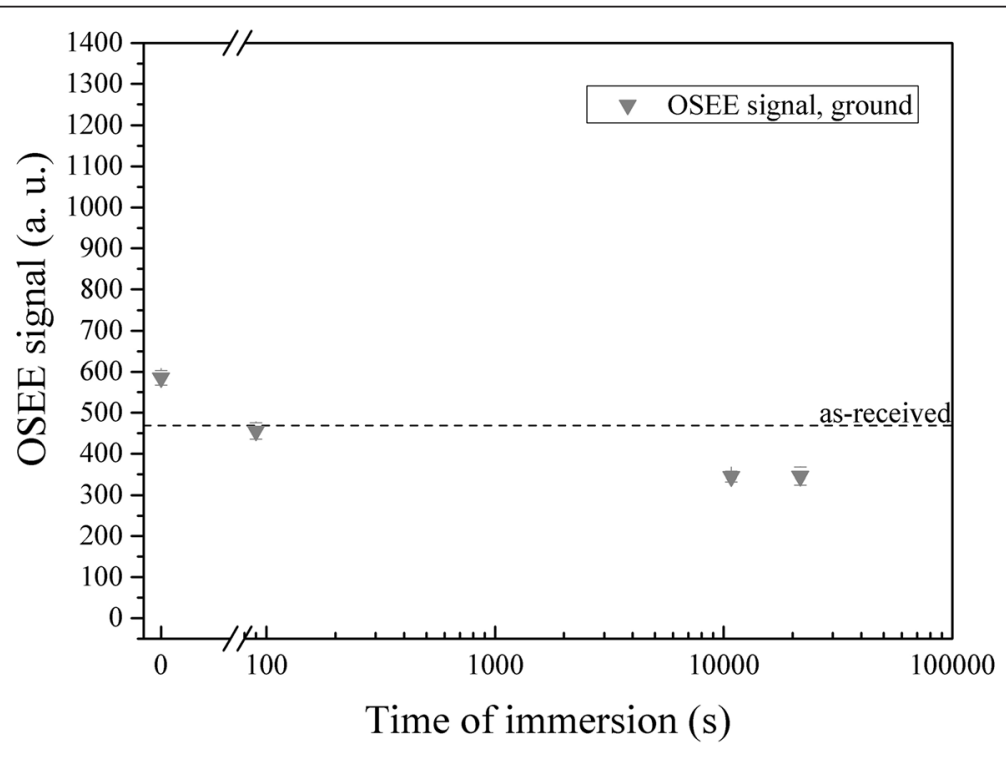

Figure 8 Results of non-destructive surface analysis using Optically Stimulated Electron Emission (OSEE) for freshly ground SAE 1008/1010 steel after immersion in water. The horizontal dashed line indicates the OSEE signal of an as-received steel sample. 
atmosphere of the workplace used for the surface pretreatment. Therefore, the exposure in air may be considered a second step of a grinding process and needs to be inspected.

Considering that OSEE signals are influenced by changes of surface states, we used this technique to follow the influence of the exposure time in air after the grinding process. Such proceeding was intended to help in identifying a maximum and a minimum open time of freshly ground steel sheets exposed to air. Following Figure 7, during an increasing exposure time in air after the grinding of both types of steel the OSEE signal of the steel panel surfaces was followed. We observed a strong decrease of the OSEE signal after comparatively short times of exposure, and for longer times in air a steady state of the steel surfaces is reached resulting in a plateau of the OSEE signal.

This information is considered relevant if grinding is used as a pretreatment, bearing in mind that the reproducibility of the output of the coating or bonding processes starting from the ground steel adherents may depend on the open time after grinding. For interpretation from the chemical point of view, we may tentatively attribute a change in the OSEE signal after exposure in air or water to a change of the state of the substrate surface [11]. The X-ray Photoelectron Spectroscopy (XPS) investigations performed for the 1.4301 steel samples show that such change affects the elemental composition of the topmost atomic layers and the thickness of the reaction layer on top of the metal bulk. XPS investigations of SAE 1008/1010 steel will reveal if such observations hold true also for this type of substrate. In any case, from the engineering point of view the surface state of an adherent in a bonding process or a substrate in a coating process may be most reliably achieved if its change after the grinding is minimal. Thus, we might expect to obtain the most reliable joint properties if the time-dependent change of the OSEE signal is minimal, and the reported observations on changes of the OSEE signal are important for the surface quality assurance during the adhesive bonding or coating process, based on reproducibly and reliably achieving a steady surface state of the steel substrates. In detail, we infer that after grinding a steel substrate a material-dependent time span of exposure in air should be waited before applying the adhesive or coating system.

\section{Extended NDT of silicone-based release agent on CFRP surfaces}

Concerning the starting state of CFRP surfaces, i.e. the untreated reference CFRP surface, before applying the selected scenarios, Figure 9 depicts that grinding resulted in carbon fibres being exposed at the surface, and area fractions each with approximately $50 \%$ were covered by carbon fibres and cured matrix resin, respectively.

Adjusting the coverage of a silicone-based release agent on CFRP sample surfaces sample preparation will be evidenced using X-ray Photoelectron Spectroscopy (XPS) which requires a destructive cutting of the CFRP samples before introducing them into an ultra-high vacuum chamber. Then the results obtained using recent NDT technologies for characterising the CFRP surfaces will be lined out.

Referring to the abscissa of Figure 10 and the respective error bars of the data points obtained, the successful application of well-defined amounts of the silicone-based release agent on ground CFRP substrates is demonstrated. While on the non-coated starting surfaces no silicon-containing species were detected, the XPS results reveal effective thicknesses of release agent in a range between approximately one nanometer and several nanometers. 


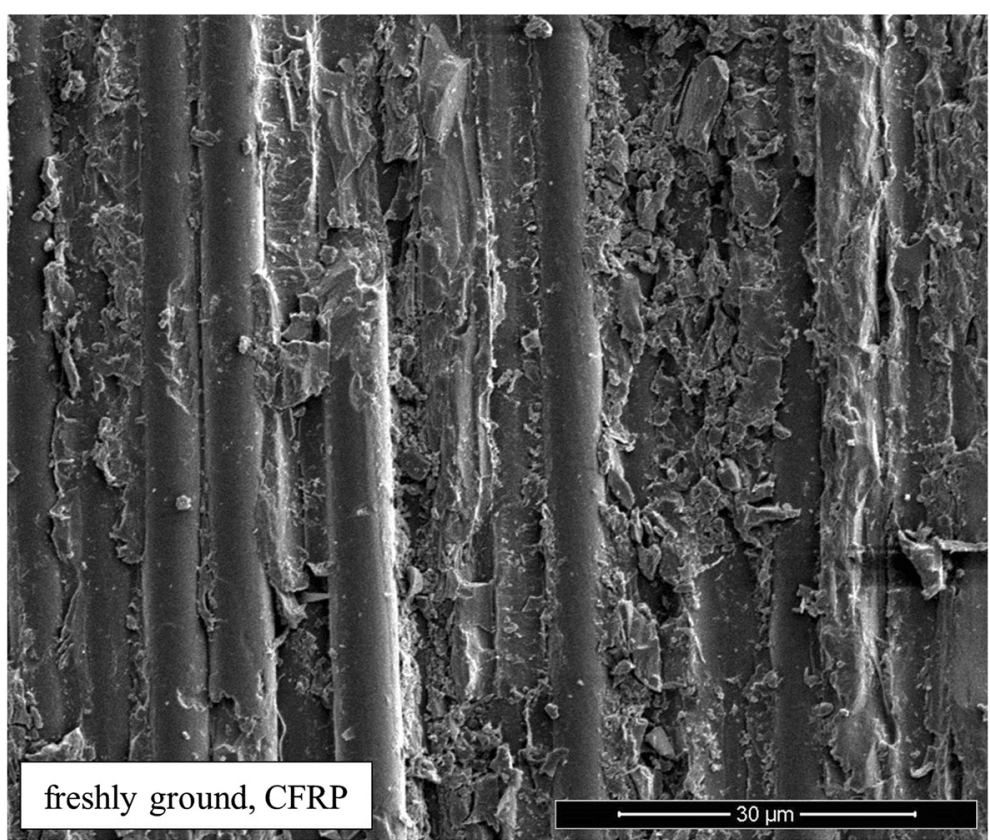

Figure 9 Scanning Electron Microscopy (SEM) based on secondary electron detection during imaging $100 \mu \mathrm{m}$ wide regions of the ground state of a carbon-fibre reinforced polymer (CFRP) surface.

Applying the NDT technologies Optically Stimulated Electron Emission (OSEE) and Aerosol-Wetting-Test (AWT) was achieved using the CFRP samples without further preparation before characterising their surfaces. Comparing the OSEE signal intensity with the concentration of silicon atoms as detected by XPS, the experimental data shown in Figure 10 clearly reveal that the signals obtained in OSEE studies are sensitive

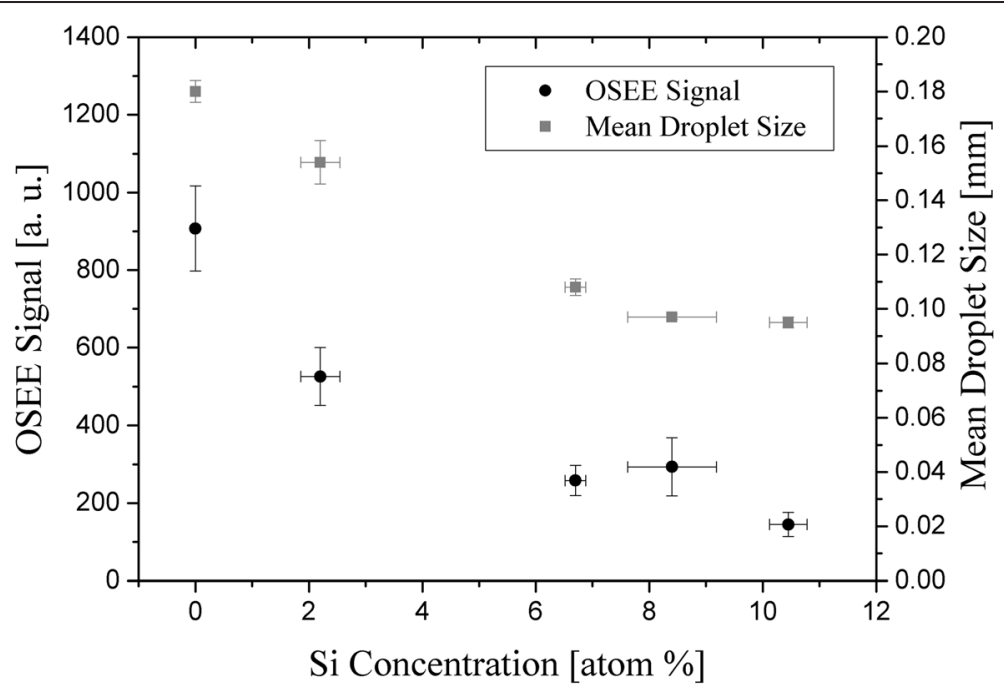

Figure 10 Results of surface quality assurance investigations of distinct states of carbon-fibre reinforced polymer (CFRP) surfaces using Optically Stimulated Electron Emission (OSEE) and Aerosol Wetting Test (AWT), respectively. The CFRP surface is covered with distinct amounts of a silicone-based release agent, as revealed by X-ray Photoelectron Spectroscopy (XPS) measurements. 
to the presence of even the thinnest layers of release agents investigated. Additionally, results from evaluating sizes of water droplets obtained from performing the AWT for CFRP surfaces free from release agent and contaminated with distinct amounts of release agent, respectively, are shown in Figure 10. For all the samples the same amount of water was applied, and the lateral dimensions and areas of imaged water drops show a size distribution. Basically, the portion of wider drops is observed to be significantly higher for the CFRP surface free from release agent which shows a better wettability with water as compared to the CFRP sample contaminated with release agent. The elaborate studies comprising a variation of the surface concentration of the release agent reveal that even at the lowest investigated thickness of the silicone-based films the average size of water drops is significantly smaller than in case of the CFRP surfaces free from release agent. That means that both OSEE and AWT investigations of CFRP adherents allow for clearly indicating the presence of a silicone-based release agent in an amount which - following Figure 1 - was demonstrated by Markatos et al. [23] to result in a strongly reduced strength of adhesive joints manufactured based on such adherents. These adherents therefore may be considered effectively contaminated. Cleaning them appropriately and testing the effect of the cleaning applying extended non-destructive testing will contribute to preventing the manufacture of adhesive joints with undesirably compromised strength.

\section{Conclusions}

Two recent non-destructive testing (NDT) technologies for the investigation of CarbonFibre Reinforced Polymer (CFRP) surfaces before adhesive bonding were assessed and advanced as a contribution to an extended non-destructive testing (ENDT) approach of composite bonds in the frame of the European FP7 project "ENCOMB - Extended nondestructive testing of composite bonds". Comparing to freshly ground CFRP surfaces, release agent contamination of the surface as a scenario relevant during CFRP application was considered. Both Optically Stimulated Electron Emission (OSEE) and AerosolWetting-Test (AWT) showed a high potential as NDT tools detecting thin layers of a silicone-based release agent on Carbon-Fibre Reinforced Polymer (CFRP) surfaces. Investigations with either of these techniques applied to adherent surfaces before the adhesive bonding process allowed to indicate the inappropriate state of potential CFRP adherents, which according to Markatos et al. [23] was related to an application scenario reducing the joint strength of resulting adhesive joints.

In case of metal substrates prone to surface reactions in presence of liquid water, AWT investigations may not be appropriate to characterize the as-received surface state but only the surface state after wet chemical treatments. Concerning non-destructive testing of SAE1008/1010 and 1.4301 steel surfaces, the results of OSEE investigations were shown to depend on the type or composition of steel, to provide information about the application of a mechanically abrasive surface pretreatment like grinding, and to reveal changes of the surface composition during exposure of the freshly ground steel substrates in reactive environments like dry air or water. As an outlook, concerning the time period between performing a mechanically abrasive pretreatment of a metal substrate - especially steel substrate surfaces - and applying the adhesive to the metal surface we suggest monitoring the material-specific open time and documenting this parameter in operating procedures for bonding processes. 
Concluding, for all these pre-bond processes engineers are facilitated to conduct appropriate revision of the adherent surface state applying the surface analytical technologies available in the frame of an extended NDT approach. Such proceeding contributes to ascertaining physico-chemical properties of adherent surfaces prior to bonding which are important for the performance of adhesive bonds. In this way, one concept aiming at quality assurance for adhesive bonding of composite or steel structures was demonstrated.

\title{
Competing interests
}

The authors declare that they have no competing interests.

\section{Authors' contributions}

KB coordinated the laboratory work for surface quality assurance, took care of the preparation of Carbon-Fibre Reinforced Polymer (CFRP) samples, and took part as well in the analysis and interpretation of the data as in drafting and revising the manuscript, CT performed Aerosol Wetting Test (AWT) measurements and the respective data evaluation, MN took part in defining and setting up the experiments with the steel samples, in analysing data and in drafting the manuscript, TW and AQ performed Optically Stimulated Electron Emission (OSEE) measurements and the respective data evaluation, TW and StSt performed the preparation and ageing tests of steel samples including their evaluation, StSt performed the lay-out and formatting of the article, TW contributed to data analysis and interpretation for the steel samples, SD and BM participated in the conception and design of the investigations and in providing information about technological boundary conditions of the surface pre-treatment and adhesive bonding processes. All authors read and approved the final manuscript.

\section{Acknowledgements}

The authors are grateful to Science without Borders (Ciência sem Fronteiras, A. F. Queiroz Barbosa 88888.049163/2013-00, and St. Stamboroski 88888.020610/2013-00) and to Coordination of Improvement of Higher Education Personnel (CAPES - Brazil). Research leading to the presented results received partial funding from the European Union's Seventh Framework Programme (FP7/2007-2013) under grant agreement number ACP0-GA-2010-266226 (ENCOMB, Extended Non-Destructive Testing of Composite Bonds). Finally, the authors acknowledge valuable hints given by a reviewer with respect to assessing steel substrates with distinct surface roughness.

\begin{abstract}
Author details
${ }^{1}$ Adhesive Bonding Technology and Surfaces, Fraunhofer Institute for Manufacturing Technology and Advanced Materials IFAM, Wiener Straße 12, D-28359 Bremen, Germany. ${ }^{2}$ Department of Mechanical Engineering, CEFET-MG, Federal Center for Technological Education of Minas Gerais, Av. Amazonas 7675, Nova Gameleira, 30510000 Belo Horizonte, MG, Brazil. ${ }^{3}$ Department of Chemistry, UFSC, Federal University of Santa Catarina, Campus Universitário Trindade, 8040-900 Florianópolis, SC, Brazil.
\end{abstract}

Received: 20 November 2014 Accepted: 19 December 2014

Published online: 11 February 2015

\section{References}

1. Brockmann W, Geiß PL, Klingen J, Schröder KB (2008) Adhesive bonding - materials, applications and technology. Wiley-VCH, Weinheim

2. Markus S, Wilken R, Dieckhoff S, Hennemann O-D (2006) Quality monitoring of CFRP surfaces in bonding and coatings processes. In: Proceedings of the 16th international conference on surface treatments in the aeronautical and space industries, surfair, Bremen, Germany

3. Stenzel V, Rehfeld N (2011) Functional coatings. Vincentz Network, Hanover

4. Schulz D (2010) Gut gereinigt ist halb geklebt. Adhäsion Kleben \& Dichten 54(7-8):18-22

5. Momber AW, Plagemann P, Stenzel V, Schneider M (2009) Investigating corrosion protection of offshore wind towers. part 3: results of the laboratory investigations. J Protective Coatings Linings 26(11):38-47

6. Klinge R (2009) Altered specifications for the protection of Norwegian steel bridges and offshore structures against corrosion. Steel Construction 2(2):109-118, doi:10.1002/stco.200910015

7. Yapp D, Blackman SA (2004) Recent developments in high productivity pipeline welding. J Braz Soc Mech Sci Eng 26(1):89-97

8. Weitzenböck JR, McGeorge D (2005) BONDSHIP project guidelines, 1st edn. Det Norske Veritas, Høvik

9. Elsner Cl, Cavalcanti E, Ferraz O, Di Sarli AR (2003) Evaluation of the surface treatment effect on the anticorrosive performance of paint systems on steel. Prog Org Coat 48(1):50-62, doi:10.1016/s0300-9440(03)00112-7

10. Sujak B, Olazowski Z, Dus-Sitek M (1983) Optically stimulated exoelectron emission and plastic properties of $\mathrm{H} 17$ steel. Radiat Prot Dosimetry 4(3/4):263-265

11. Momose Y, Namekawa T (1978) Exoelectron emission from metals subjected to friction and wear, and its relationship to the adsorption of oxygen, water vapor, and some other gases. J Phys Chem 82(13):1509-1515

12. Abedin MN, Welch CS, Yost WT (1991) Review of progress in quantitative nondestructive evaluation. Vol. 11B. In: Proceedings of the 18th Annual Review, Brunswick, ME, July 28-Aug. 2, 1991 (A93-19582 06-38), pp 1799-1805

13. Davis GD (1993) Contamination of surfaces: origin, detection and effect on adhesion. Surf Interface Anal 20:368-372

14. Venables JD (1984) Adhesion and durability of metal-polymer bonds. J Mater Sci 19:2431-2453

15. Gledhill RA, Kinloch AJ, Shaw SJ (1977) Effect of relative humidity on the wettability of steel surfaces. J Adh 9(1):81-85, doi:10.1080/00218467708075101 
16. Baldan A (2004) Adhesively-bonded joints and repairs in metallic alloys, polymers and composite materials: adhesives, adhesion theories and surface pretreatment. J Mater Sci 39(1):1-49

17. Harris AF, Beevers A (1999) The effects of grit-blasting on surface properties for adhesion. Int J Adh Adhesives 19(6):445-452, doi:10.1016/s0143-7496(98)00061-X

18. Poorna Chander K, Vashista M, Sabiruddin K, Sabiruddin K, Paul S, Bandyopadhyay PP (2009) Effects of grit blasting on surface properties of steel substrates. Mat Design 30(8):2895-2902, doi:10.1016/..matdes.2009.01.014

19. Griffiths BJ, Gawne DT, Dong G (1996) The erosion of steel surfaces by grit-blasting as a preparation for plasma spraying. Wear 194(1-2):95-102, doi:10.1016/0043-1648(95)06798-1

20. Multigner M, Ferreira-Barragáns S, Frutos E, Jaafar M, Ibáñez J, Marín P, Pérez-Prado MT, González-Doncel G, Asenjo A, González-Carrasco UL (2010) Superficial severe plastic deformation of 316 LVM stainless steel through grit blasting: effects on its microstructure and subsurface mechanical properties. Surf Coat Technol 205(7):1830-1837, doi:10.1016/j.surfcoat.2010.07.126

21. Collazo A, Fernández D, Izquierdo M, Nóvoa XR, Pérez C (2005) Evaluation of red mud as surface treatment for carbon steel prior painting. Prog Org Coat 52(4):351-358, doi:10.1016/j.porgcoat.2004.06.008

22. Parker BM, Waghorne RM (1991) Testing epoxy composite surfaces for bondability. Surf Interface Anal 17:471-476, doi:10.1002/sia.740170710

23. Markatos DN, Tserpes Kl, Rau E, Markus S, Ehrhart B, Pantelakis S (2013) The effects of manufacturing-induced and in-service related bonding quality reduction on the mode-l fracture toughness of composite bonded joints for aeronautical use. Composites Part B Eng 45(1):556-564, doi:10.1016

24. Brune K, Lima L, Noeske M, Thiel K, Tornow C, Dieckhoff S, Hoffmann M, Stübing D (2013) Pre-bond quality assurance of CFRP surfaces using optically stimulated electron emission. Proceedings of the 3rd International Conference of Engineering Against Failure. ICEAF, Kos, Greece, p 300-307

25. Wilken R, Markus S, Amkreutz M, Tornow C, Seiler A, Dieckhoff S, Meyer U (2008) Method and device for testing a surface quality. EP1893974 B1

26. Garcia Gonçalves LM, Sanchez LC, Stamboroski S, Corrales Urena YR, Leite Cavalcanti W, Ihde J, Noeske M, Soltau M, Brune K (2014) Instantly investigating the adsorption of polymeric corrosion inhibitors on magnesium alloys by surface analysis under ambient conditions. J Surf Eng Mat Adv Technol 4:282-294

27. Q-Lab Corporation (2014). http://www.q-lab.com/de-de/products/q-panel-standard-substrates/q-panel-selector. Accessed 14 Nov 2014

28. Deutsche Edelstahlwerke GmbH (2014). http://www.dew-stahl.com/fileadmin/files/dew-stahl.com/documents/ Publikationen/Werkstoffdatenblaetter/RSH/1.4301_de.pdf. Accessed 14 Nov 2014

\section{Submit your manuscript to a SpringerOpen ${ }^{\circ}$ journal and benefit from:}

- Convenient online submission

- Rigorous peer review

- Immediate publication on acceptance

- Open access: articles freely available online

- High visibility within the field

- Retaining the copyright to your article 